\title{
BEEF CONSUMER PREFERENCES IN CHILE: IMPORTANCE OF QUALITY ATTRIBUTE DIFFERENTIATORS ON THE PURCHASE DECISION
}

\author{
Pablo Villalobos ${ }^{1 *}$, Carlos Padilla ${ }^{1}$, Cristian Ponce ${ }^{1}$, and Álvaro Rojas ${ }^{1}$
}

\begin{abstract}
Agrifood markets worldwide have focused on searching for new quality attribute differentiators, which capture the attention of consumers and meet their needs. The purpose of this research was to determine the importance of a set of quality attribute differentiators associated with a beef cut on the choice behavior of the Chilean consumer. The evaluated differentiating characteristics were: price, origin, production method, and quality assurance. A total of 750 subjects were surveyed in the following cities: Talca, Rancagua, and Santiago. Conjoint analysis was carried out to estimate the impact of the assessed attributes on the purchase decision of the consumers polled. Findings point out that the quality attribute differentiators significantly influence consumer choice behavior, with price being the least important for the majority of consumers polled (21.07\% relative importance for the whole sample). In this context, the quality assurance attribute is shown as the most relevant which guides the decision-making process of beef consumers (29.75\% relative importance for the whole sample). Even though some limitations are shown within this study, it must be emphasized that the results follow similar trends already described in previous research carried out in other countries. These tendencies should be considered, therefore, to establish differentiation strategy tools when designing a marketing mix focused on the domestic market.
\end{abstract}

Key words: conjoint analysis, country of origin, animal welfare, quality assurance, differentiation, marketing.

\section{INTRODUCTION}

Consumer demand for optimum quality products has increased considerably in virtue of available information and the degree of competitiveness within the agrifood chains. This fact has promoted market growth of highly differentiated agricultural products through a series of attributes (search, experience, and credibility) and quality indicators (intrinsic and extrinsic) associated with the product and the productive processes (Becker, 2000; Northen, 2000). Diverse studies have documented that in the particular case of meat products, attributes such as animal welfare (AW), quality assurance, and the country of origin notably influence the consumer's purchase decision, acting as quality and innocuousness indicators in some cases (Walley et al., 1999; Becker et al., 2000; Hoffmann, 2000; Meehan et al., 2002; Bernués et al., 2003a; 2003b; Bernabéu and Tendero, 2005; Mesías et al., 2005).

${ }^{1}$ Universidad de Talca, Facultad de Ciencias Agrarias, Casilla 747, Talca, Chile. "Corresponding author (pvillal@utalca.cl).

Received: 16 October 2008.

Accepted: 05 May 2009.
The product origin attribute is associated with a set of characteristics typical of the geographical environment, culinary traditions, product manufacturing methods, and the sense of national identity (Han, 1998; as cited by Knight, 1999). In the particular case of beef, a study carried out by Hoffmann (2000) indicates that the country of origin attribute is a factor directly associated with the quality of the meat product. In the same way, Becker et al. (2000) established that this attribute is used by meat consumers, not only as a quality parameter of consumption, but also as an indicator of food innocuousness. More recently, Mesías et al. (2005) indicated that the origin of beef was the most determining attribute guiding the purchase decision in a study carried out in Spain. This concurs with results obtained by other authors (Bernués et al., 2003b). It has been determined that in some cases however, information about product quality through labels would be more relevant for beef consumers (Verbeke and Ward, 2006).

The AW is a concept associated not only with production methods respectful of the care and protection of animals during the breeding cycle, transportation, and slaughter, but also related to the quality and food innocuousness of the final meat product (Meehan et al., 2002; Villalobos, 
2005). As pointed out in the study by Meehan et al . (2002), consumers perceive and relate the term AW to other attributes of meat products such as product quality and innocuousness; both highly relevant in the purchase decision. As far as ethical considerations are concerned with respect to AW, these would also be influenced by consumer preferences for meat products (Bernués et al., 2003a). This concurs with results obtained by Mesías et al. (2005) who determined, through preference analysis, that the use of production methods that lead to better AW has a positive impact on the consumer's purchase decision. This tendency is empirically supported by some studies which point out that meat coming from systems that take into account AW have better organoleptic characteristics (Tadich et al., 2000; Gallo et al., 2003).

Consumer distrust toward public quality control systems, innocuousness, and traceability of foods (Jahn et al., 2005) has promoted the incorporation of modern monitoring systems, mainly private, in the different links of the agrifood chains (Spiller, 2003; Hatanaka et al., 2005). The public sector has reacted by generating agrifood policies tending to provide greater protection to the consumer (European Commission, 2005). Walley et al. (1999), carrying out a preference analysis for a set of attributes associated with beef, determined that quality assurance is an important factor in making a purchase decision with consumers preferring meat produced under quality assurance standards over a meat product not offering this attribute. Similar results are shown in a previous study by Huang and $\mathrm{Fu}$ (1993).

Regarding the price of products, some research studies carried out in more developed agrifood markets point out that this factor would have little influence on consumer decisions compared to quality attribute differentiators (Huang and Fu, 1993; Walley et al., 1999; Glitsch, 2000). It seems that the importance of price in the consumer decision has declined in more industrialized countries in favor of the search for attributes providing security and decreasing the consumer's perception of risk (Mesías et al., 2005).

In general, this study contributes key market information to generate marketing strategies in the Chilean beef industry. More specifically, i) the importance of quality attributes previously described on the purchasing behavior of beef consumers in Chile, and ii) the implications of consumer decisions on the Chilean beef industry were determined.

\section{MATERIALS AND METHODS}

\section{Theoretical framework}

To investigate consumer preferences, the conjoint analysis (CA) method was used in this study. This method is based on the consumer demand theory developed by Kevin Lancaster (Lancaster, 1966), who proposes that the attributes or factors that make up a good will benefit individuals and that every good satisfies a set of attributes and specific levels. Therefore, Lancaster's model assumes that the total utility of a good is a function of a set of attributes and each individual acquires goods with the sole purpose of obtaining attributes that provide utility or satisfaction. Lancaster's approach provides a theoretical framework to analyze consumer preferences and purchasing behavior with regards to multi-attribute decisions. In this context, AW may be seen as an extension of Lancaster's utility model as it begins with the hypothesis that purchasing behavior can be interpreted as a choice among different products possessing a set of attribute or characteristic differentiators (Varela and Braña, 1996).

AW corresponds to a multivariate analysis technique that separates, in terms of utility, the overall judgments that consumers make for a determined product concept (Green and Srinivasan, 1978; 1990). According to Varela and Braña (1996), we can also talk about a research method or methodology. The concept of utility is the basis for measuring the value of AW and corresponds to a subjective judgment of a unique preference for each individual (Hair et al., 1999). In other words, utility corresponds to a quantitative mean of the value that the consumer assigns to distinct levels of a set of attributes that make up a determined product (Intelliquest, 2000). For a model to be valid, total utility derived from the analyzed products must correspond as much as possible to the original range of preferences established by the consumers being consulted (Varela and Braña, 1996; Aaker et al., 2003). Moreover, estimated utility can be used to calculate the relative importance of product attributes (Green and Srinivasan, 1978; Varela and Braña, 1996; Hair et al., 1999).

To get a broader view of the practical application of this method in the agrifood industry, it is recommended to consult the following authors: Jaeger et al. (2001); van der Lans and van Ittersum (2001); Bech-Larsen and Grunert (2003); Fotopoulos and Krystallis (2003); Murphy et al. (2004); Mesías et al. (2005); O'Connor et al. (2005); Tendero and Bernabéu (2005); Lockshin et al. (2006); O'Connor et al. (2006); Belcher et al. (2007); Padilla et al. (2007), among others.

There are basic steps to follow during the design of a conjoint study (Green and Srinivasan, 1978; 1990; Varela and Braña, 1996; Hair et al., 1999; Intelliquest, 2000). Nevertheless, the order and number of steps can vary according to each author. In the context of this research, the steps were the following: i) selection of attributes and attribute levels, ii) preference model, iii) data collection 
method, iv) stimuli construction, v) stimuli presentation, and vi) utility estimation.

For the particular case of this study, the product "posta de vacuno" (beef round) was selected because it is a widely used beef cut in Chilean households without regards to the socioeconomic strata to be analyzed. In the same way, and considering the central objective of this research and the literature background previously mentioned, four attributes were selected: i) price, ii) country of origin of the product, iii) production system, and iv) quality assurance. The levels chosen for each attribute are shown in Table 1.

The price attribute levels were selected from the information on prices in the national market for $1 \mathrm{~kg}$ of beef round. With the purpose of fixing an average price per kilogram of product, both supermarkets and butcher shops were visited in Talca. Finally, an average price of CLP $\$ 3290 \mathrm{~kg}^{-1}$ (CLP\$529 = USD\$1) was estimated. On the basis of this average price, increments of CLP $\$ 250$ (USD $\$ 0.47$ ) and CLP \$500 (USD \$0.95), respectively, were made to obtain the remaining price levels considered in this study. The levels assigned to the remaining attributes responded to the absence or presence of the differentiating characteristic of the product (quality assurance and production system), and in the case of country of origin, the main beef suppliers in the national market, as well as Chilean suppliers, were considered during the period this study was carried out.

An additive type model was used for the composition rule. The composition rule describes how the subject who is consulted combines the partial components of the total utility of the attributes to obtain a conjoint value of a combination (Hair et al., 1999). In an additive model preference for a determined product is assumed as an additive function of the utility of its components

Table 1. Selected attributes and attribute levels for the conjoint exercise.

\begin{tabular}{ll}
\hline Attribute name & Attribute level \\
\hline Price $^{1}$ (per kg) & CLP $\$ 3290$ \\
& CLP $\$ 3540$ \\
& CLP $\$ 3790$
\end{tabular}

Country of origin Chile

Argentina

Brazil

Production system

Conventional

Incorporates animal welfare

Quality assurance $\quad$ Yes

No or attributes (Green and Srinivasan, 1978; Cattin and Wittink, 1982; Wittink and Cattin, 1989). That is, the dependent variable corresponds to the overall preference judgment that the subject carries out with respect to a product while the independent variables correspond to the specified attribute levels. Considering the variables evaluated in this study, overall preference or total utility of a combination $(\mathrm{R})$ can be expressed by the following mathematical expression:

$\mathrm{R}=$ Uprice $_{i}+$ Uorigin $_{j}+$ Usystem $_{k}+$ Uquality $_{l}+$ constant

where: Uprice $_{i}=$ utility of level $i$ of the price attribute, Uorigin $_{j}=$ utility of level $j$ of the country of origin attribute, Usystem $_{k}=$ utility of level $k$ of the production system attribute, and Uquality ${ }_{l}=$ utility level $l$ of the quality assurance attribute.

To estimate preference functions, in the case of the price attribute, a linear relationship was established for the assigned levels. This is because in general a higher price means utility or preference is lower. For the remaining attributes, a part-worth model was assigned to explain how the levels of each factor in the conjoint model are related (Green and Srinivasan, 1978; 1990; Hair et al., 1999).

Once the attributes and attribute levels were selected, the way to collect necessary data to proceed with utility estimation was determined. In the specific case of this study, the complete focus profile was chosen and implemented by means of a specially designed questionnaire. The special feature of this method rests in that the proposed product is a particular combination of all the possible attribute characteristics, thus allowing a direct measuring of the overall consumer preference judgment (Green and Srinivasan, 1990).

Once the complete profile method was chosen to collect data, the option was made to use a fractional factorial experimental design to construct the product concepts or profiles to be evaluated (Green and Srinivasan, 1978; 1990; Varela and Braña, 1996; Hair et al., 1999; Intelliquest, 2000). This design is also known as orthogonal design or arrangement corresponding to a subgroup of all the possible combinations, assuming the independence of the principal effects (attributes), thus depreciating interactions (Varela and Braña, 1996; Hair et al., 1999). The orthogonal design was generated by the use of the algorithm included in the SPSS version 12.0 statistical package. As a result of this procedure, nine hypothetical product profiles were created (Table 2). Furthermore, two concepts of additional products (validation profiles) were included with the purpose of verifying the predictive validity of the conjoint model (Green and Srinivasan, 1978; 1990). 
Table 2. Orthogonal array for beef round.

\begin{tabular}{lllll}
\hline Product & $\begin{array}{c}\text { Quality } \\
\text { assurance }\end{array}$ & \multicolumn{1}{c}{$\begin{array}{c}\text { Production } \\
\text { system }\end{array}$} & $\begin{array}{c}\text { Country } \\
\text { of origin }\end{array}$ & Price $^{\mathbf{1}}$ \\
\hline & & & & $\mathbf{\$ \mathbf { k g } ^ { - 1 }}$ \\
1 & Yes & Conventional & Brazil & 3540 \\
2 & Yes & Conventional & Chile & 3290 \\
3 & No & Conventional & Argentina & 3790 \\
4 & Yes & Conventional & Chile & 3790 \\
5 & No & Incorporates animal welfare & Chile & 3540 \\
6 & Yes & Conventional & Argentina & 3540 \\
7 & Yes & Incorporates animal welfare & Brazil & 3790 \\
8 & No & Conventional & Brazil & 3290 \\
9 & Yes & Incorporates animal welfare & Argentina & 3290 \\
$10^{2}$ & Yes & Conventional & Argentina & 3290 \\
$11^{2}$ & No & Incorporates animal welfare & Brazil & 3790 \\
\hline
\end{tabular}

${ }^{1}$ CLP \$529 = USD \$1.

${ }^{2}$ Correspond to validation profiles.

The two most frequent ways to show created product profiles are: verbal description and photographic representation as well as the possibility of combining the two (Green and Srinivasan 1978; Cattin and Wittink, 1982; Wittink and Cattin, 1989; Hair et al., 1999; Intelliquest, 2000). A variation of the verbal description procedure was used in this research. The questionnaire included instructions so that the persons polled who were unfamiliar with the terms AW and quality assurance could be familiarized with these concepts before completing the conjoint exercise.

To carry out utility estimation, the CONJOINT procedure of the SPSS version 12.0 statistical package was executed (Pérez, 2005).

\section{Research design}

The conjoint exercise was implemented by a survey with a total of 750 copies of a self-administered questionnaire of a non-probabilistic sample consisting of 250 subjects from each of the cities of Talca, Rancagua, and Santiago. It is worth noting that a defined sampling framework was not used in this study to select the subjects. Sectors or communes were selected in each city taking into consideration the socioeconomic distribution of the households. The survey took place over the period between September and November 2005. The questionnaire in this study was applied using the drop-off/pick-up method since it allows obtaining higher response rates at a cost lower than other methods (Lovelock et al., 1976). In each sector or commune previously selected, the questionnaire was distributed to households that were willing to participate in the study. The questionnaire was picked up by the pollsters after a reasonable time period. Of the total questionnaires distributed in the different cities, 649 copies were recovered which is equivalent to a response rate of $86.5 \%$. For the data analysis procedure, however, only 521 questionnaires were considered valid of which 146 corresponded to Talca, 184 to Rancagua, and 191 to Santiago.

The selected sampling unit corresponded to those persons in charge of grocery shopping in the household or at least participating in this task. To establish this, a filter question was included at the beginning of the questionnaire. Before administering the questionnaire in the three cities, a pilot study was carried out with some consumers from Talca with the purpose of verifying the consistency and understanding of the measurement tool. A final version of the questionnaire was prepared after the pilot study taking into consideration the difficulties detected in the self-administered survey. Both verbal and written specific instructions were given for answering each section of the questionnaire when the final official version was distributed, thus ensuring understanding by the subjects being polled.

The questionnaire was subdivided in six main sections. The first section included questions related to the purchasing behavior of the consumers toward beef. In the second section subjects were asked about their preferences for the product profiles designed in this research. Stimuli were ordered and shown in a table following the result given by the experimental design (Table 2). In this way, those polled had to assign their preferences correlatively from 1 to 11 with 1 being the most preferred product and 11 the least.

The third section of the questionnaire included attitude and knowledge questions about topics related to meat 
quality and AW. The fourth section included a contingent assessment scenario with the objective of estimating the disposition of those polled to pay for attributes such as AW and quality assurance. Finally, the last section considered socioeconomic questions. It is worth noting that in this article only the results of this conjoint exercise and the sample description are presented.

\section{RESULTS AND DISCUSSION}

\section{Descriptive analysis of the sample}

Differences were established with contingency tables and Chi-square among cities (Table 3) in terms of socioeconomic variables.

By analyzing the whole sample structure, it can be seen that the majority of those polled were female. This concurs with the results obtained by Padilla et al. (2007). With respect to the age of those polled, the sample follows a pattern similar to a normal distribution. In terms of education, university and technical training dominate. The number of family members varied between 3-4 and 5-6 persons. Most of those polled indicated a monthly family income $\leq$ CLP $\$ 800000$ (USD \$1512).

Significant differences among cities were detected for the gender, education, and family income variables. In general terms, the composition of the Talca and Rancagua sample showed a similar structure with respect to these variables and followed a behavior pattern similar to that described for the whole sample. On the contrary, the Santiago sample was made up mostly of male. The educational level of those polled, though concentrated between university and technical training, also tended

Table 3. Socioeconomic variables for the whole sample by city.

\begin{tabular}{|c|c|c|c|c|c|}
\hline Variables & $\begin{array}{c}\text { Total } \\
n=521\end{array}$ & $\begin{array}{c}\text { Talca } \\
n=146\end{array}$ & $\begin{array}{c}\text { Rancagua } \\
n=184\end{array}$ & $\begin{array}{c}\text { Santiago } \\
n=19\end{array}$ & Chi-square \\
\hline & & 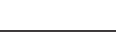 & 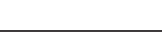 & - & \\
\hline Gender** & & & & & 10.194 \\
\hline Male & 43.6 & 41.1 & 36.4 & 52.4 & \\
\hline Female & 56.4 & 58.9 & 63.6 & 47.6 & \\
\hline Age & & & & & 8.439 \\
\hline$<25$ & 10.2 & 10.3 & 10.9 & 9.4 & \\
\hline $25-34$ & 32.6 & 26.0 & 35.9 & 34.6 & \\
\hline $35-44$ & 25.9 & 25.3 & 23.4 & 28.8 & \\
\hline $45-54$ & 20.3 & 26.0 & 20.1 & 16.2 & \\
\hline$>54$ & 10.9 & 12.3 & 9.8 & 11.0 & \\
\hline Education $^{* *}$ & & & & & 33.545 \\
\hline Elementary & 4.0 & 4.1 & 0.5 & 7.3 & \\
\hline Secondary & 21.9 & 17.8 & 23.4 & 23.6 & \\
\hline Technical & 28.6 & 26.7 & 34.8 & 24.1 & \\
\hline University & 40.5 & 46.6 & 40.8 & 35.6 & \\
\hline Postgraduate studies & 5.0 & 4.8 & 0.5 & 9.4 & \\
\hline Family Group & & & & & 10.925 \\
\hline $1-2$ & 14.8 & 15.1 & 16.8 & 12.6 & \\
\hline $3-4$ & 42.6 & 46.6 & 45.7 & 36.6 & \\
\hline $5-6$ & 35.9 & 34.9 & 30.4 & 41.9 & \\
\hline$>6$ & 6.7 & 3.4 & 7.1 & 8.9 & \\
\hline Family income & & & & & 13.642 \\
\hline$<\$ 350001^{1}$ & 25.3 & 21.9 & 28.8 & 24.6 & \\
\hline$\$ 350001-\$ 800000$ & 40.9 & 46.6 & 43.5 & 34.0 & \\
\hline$\$ 800001-\$ 1400000$ & 21.9 & 22.6 & 15.2 & 27.7 & \\
\hline$>\$ 1400000$ & 11.9 & 8.9 & 12.5 & 13.6 & \\
\hline
\end{tabular}

***Indicates significant differences among cities at the $1 \%$ probability level.

"Indicates significant differences among cities at the 5\% probability level.

${ }^{1}$ Chilean pesos (CLP \$529= USD \$1). 
to disperse toward elementary education and graduate studies. With respect to family income, a considerable number of those polled in Santiago indicated a family income > CLP $\$ 800000$ (USD \$1512).

\section{Conjoint analysis}

In Table 4 the utility estimated with the conjoint method is shown for the whole sample and for the cities. In the same way, relative importance was calculated for each attribute.

In the case of the whole sample, the correlation between the observed preferences and those estimated with the conjoint model (Kendall's Tau-b $=0.944 ; p=$ 0.0002) indicates the high degree of model adjustment. In the same way, the estimated correlation for the set of validation combinations (Kendall's Tau-b $=1.000 ; p=$ 0.0000 ), points out that the model has a high predictive ability. In other words, the estimated conjoint model has internal and predictive validity. Likewise, the observed and estimated preference values for each city show a high degree of adjustment (Kendall's Tau-b $=1.000$ for all cases), which guarantees consistency and validity of the estimated models.

The lowest price for the whole sample reached the highest utility while the highest price achieved the lowest utility score, which is consistent with economic theory. Considering the country of origin attribute, Chile reached the highest utility score while those polled assigned a lower utility to Argentina and Brazil. Bearing in mind that Chile is a country with a better zoosanitary status than that of Argentina and Brazil, and in accordance with Becker et al. (2000), preference for a meat product of national origin would indicate that Chilean consumers would use the product origin attribute as an indicator of innocuousness and beef quality. Therefore, a beef cut of national origin would help to reduce the consumer's perception of risk, strongly influencing his/her purchase decision. Accordingly, a production system which considers AW standards delivers the highest utility to those polled. This result can be based on the fact that consumers perceive and relate the term AW with other meat product attributes such as product quality and innocuousness (Meehan et al., 2002).

Likewise, ethical considerations toward AW could positively influence the consumer's preference and purchase decision (Bernués et al., 2003a; Mesías et al., 2005). It is interesting to observe how the AW attribute is gaining strength in consumer choice when expressing their intention to purchase. Villalobos (2005) reported that domestic consumers tend to prefer a meat product produced under AW standards over one coming from a conventional production system. With respect to the quality assurance attribute, the results show that consumers polled in this study assigned a higher utility level to a product obtained by processes that consider the implementation of protocols ensuring its quality. This fact is consistent with previous research results (Huang and Fu, 1993; Walley et al., 1999), which indicate that quality assurance is a factor affecting consumer purchasing behavior in an important way.

The utility estimated with the conjoint models for each city tends to be similar to the results obtained for the whole sample. However, in the case of Santiago, when considering the country of origin attribute, it can be seen that the Argentina level is the one to which consumers assign the highest utility value, followed by Brazil and Chile, respectively. This difference could be based on the degree of ethnocentrism or nationalism of the consumers polled. The term "consumer ethnocentrism" is used to represent the beliefs of consumers about the convenience or morality of buying products manufactured or coming from abroad (Shimp and Sharma, 1987), and influences the intention to purchase due to the effect of nationalistic emotions on consumer behavior (Kaynak and Kara, 2002). In spite of the fact that the variable of consumer ethnocentrism was not measured in this study, it is interesting to emphasize that some research studies indicate that the groups with the highest income, high educational level, and male, do not tend to be ethnocentrists (Watson and Wright, 2000; Kaynak and Kara, 2002; Javalgi et al., 2005). These socioeconomic characteristics precisely dominate in the consumers polled in Santiago, that is, consumers in this city would tend to not be ethnocentrists, and therefore, would have a positive perception toward beef coming from other countries such as Argentina and Brazil, and be inclined to prefer these products. Another important aspect is that consumers living in regions other than the Metropolitan Region are less exposed to influences from other countries and are more attached to national traditions than consumers from the capital city. This fact could promote a higher degree of ethnocentrism in those consumers living in regions other than the Metropolitan Region, and therefore, incline their preferences toward products of national origin.

The previous analysis presents an important implication for the design of marketing strategies. For example, beef distributors (supermarkets, butcher shop chains) should establish differentiated marketing strategies according to the origin of their products and where they are commercialized. As a result, it would be recommendable to offer a greater quantity of beef of national origin in regions outside Santiago, while imported meat should dominate the displays and shelves in the capital.

To have an idea of the importance of each attribute on consumer choice behavior, their relative importance was calculated following the methodology used by other authors in previous studies (Halbrendt et al., 1995; 
Table 4. Estimated utility and relative importance of the attributes for the whole sample by city.

\begin{tabular}{lcccc}
\hline & \multicolumn{3}{c}{ Estimated utility } \\
\cline { 2 - 4 } Attributes/Levels/Relative Importance & Sample & Talca & Rancagua & Santiago \\
\hline Constant & 13.3954 & 10.3658 & 18.5382 & 10.4857 \\
Price $^{1}$ & & & & \\
CLP $\$ 3290$ & -7.9482 & -5.3481 & -5.1257 & -1.2655 \\
CLP $\$ 3540$ & -8.5522 & -5.7545 & -5.5152 & -1.3616 \\
$\quad$ CLP $\$ 3790$ & -9.1561 & -6.1609 & -5.9047 & -1.4578 \\
Relative importance & 21.07 & 16.79 & 17.69 & 27.61 \\
Country of origin & & & & \\
$\quad$ Chile & 0.4069 & 1.0342 & 0.5507 & -0.2112 \\
Argentina & -0.0614 & -0.3311 & -0.0797 & 0.1623 \\
$\quad$ Brazil & -0.3455 & -0.7032 & -0.4710 & 0.0489 \\
Relative importance & 27.27 & 32.51 & 23.65 & 26.75 \\
Production system & & & & \\
$\quad$ Conventional & -0.7083 & -0.5462 & -0.8750 & -0.6715 \\
$\quad$ Animal welfare & 0.7083 & 0.5462 & 0.8750 & 0.6715 \\
Relative importance & 21.91 & 17.64 & 25.47 & 21.73 \\
Quality assurance & & & & \\
Yes & 1.1785 & 1.3527 & 1.3234 & 0.9058 \\
$\quad$ No & -1.1785 & -1.3527 & -1.3234 & -0.9058 \\
Relative importance & 29.75 & 33.06 & 33.19 & 23.91 \\
\hline
\end{tabular}

${ }^{1}$ CLP $\$ 529=$ USD $\$ 1$.

Harrison et al., 1998; Tendero and Bernabéu, 2005; Padilla et al., 2007). The estimate of the relative importance of the attributes for the whole sample indicates that quality assurance is the most important attribute that would be guiding the consumer's purchase decision process. Following in terms of importance are: country of origin, production system, and finally, price. These results concur with those pointed out in research studies carried out in other countries (Huang and Fu, 1993; Walley et al., 1999; Becker et al., 2000; Glitsch, 2000; Hoffmann, 2000; Meehan et al., 2002; Bernués et al., 2003a; 2003b; Bernabéu and Tendero, 2005; Mesías et al., 2005). Therefore, the beef consumer at a domestic level would not only use price as a decision factor at the moment of choosing a beef cut, but would also use another type of attributes, for example, those related to product quality and those which provide characteristic differentiators.

By considering the relative importance of the attributes for the segmented city samples, it can be seen that Talca and Rancagua follow a pattern similar to the one described for the whole sample; the quality assurance attribute being the most important for the consumers polled when making a purchase decision. Price continues to be the least important attribute. For the consumers polled in Talca and Rancagua, the incorporation of quality management tools in the beef chain is fundamental when making a purchase decision. A notable difference can be observed in Santiago where the price attribute dominates the structure of consumer preferences while quality assurance is secondary. This difference could be justified by the fact that the cost of living is higher in Santiago than in the other regions. Although a greater number of those polled receive an income > CLP $\$ 800000$ (USD\$1512), as compared to Talca and Rancagua (Table 3), in real terms, this amount could be less due to the higher cost of living in the capital. Thus, consumers in the capital would have a more restricted food budget and price would be a determining factor for them when choosing among various alternatives.

In spite of the consistency of the results obtained as pointed out in previous studies, some limitations of this study must be considered mainly from the methodological point of view. Firstly, it must be considered that this research study worked with a non-probabilistic sampling system which does not allow making an inference about the population being studied. On the one hand, there could have been some influence in the preferences observed in Talca and Rancagua due to the little difference between 
price levels chosen for the conjoint evaluation. However, these differences were enough to exert an important effect on the preferences of consumers interviewed in Santiago. On the other hand, in a conjoint exercise, it is recommended to change the order in which the product profiles are presented to those interviewed to avoid order bias. This was not done in this study because of the way in which the stimuli were presented and for practical considerations. Furthermore, it must be emphasized that the quality assurance methodology only gives a vision of the consumer's intention to purchase, which does not necessarily represent real consumer behavior when choosing among various alternatives in daily life. Furthermore, it is recommendable to evaluate another type of attributes that could have an impact on the consumer's beef purchase decision, for example, fat content, freshness, packaging, labeling, among others. In the same way, the results presented must be analyzed within the economic and market context in which data collection was carried out in the field. Therefore, any attempt to analyze the results in another scenario could lead to confusion in their interpretation.

In spite of the above-mentioned, there are clear signals that Chilean consumers are modifying their choice habits, considering quality attribute differentiators over economic aspects when purchasing. Perhaps this situation is an opportunity for the national meat industry to initiate a marketing strategy to differentiate its products and make them more competitive at a domestic level.

\section{CONCLUSIONS}

The utility estimated by means of the methodology used in this study leads to the conclusion that beef of national origin, which is produced under protocols that consider animal welfare and a production process with norms that ensure product quality, is a highly attractive product for the majority of the consumers polled in this study.

Regarding the evaluated attributes, quality assurance exerts the greatest influence on the choice behavior of the consumers polled, and price is the least important attribute for the majority of them.

Tendencies shown in this research, and in previous studies, point out that the Chilean beef industry should consider some strategic differentiation tools when it comes to the design of a marketing mix focused on the domestic market.

Finally, it is necessary to pursue a careful study of national consumer preferences, eating habits, and attributes that guide the purchase decision since the results described in this article indicate the necessity to look for new alternatives that satisfy the demand of those emerging market niches.

\section{RESUMEN}

Preferencias del consumidor de carne de vacuno en Chile: Importancia de atributos de calidad diferenciadores en la decisión de compra. Los mercados agroalimentarios a nivel mundial se han focalizado en la búsqueda de nuevos atributos de calidad diferenciadores que capten la atención de los consumidores y satisfagan sus necesidades. El propósito de esta investigación fue determinar la importancia que ejerce un conjunto de atributos de calidad diferenciadores asociados a la carne de vacuno, en la decisión de compra del consumidor chileno. Los atributos evaluados fueron: precio, origen del producto, sistema de producción y aseguramiento de la calidad. Un total de 750 personas fueron consultadas a través de una encuesta en las ciudades de Talca, Rancagua y Santiago. Por su parte, la estimación del impacto de los atributos evaluados en la decisión de compra de los consumidores consultados, se llevó a cabo utilizando el método de análisis conjunto. Los resultados indican que los atributos de calidad diferenciadores ejercen una alta influencia sobre el comportamiento de elección del consumidor, siendo el precio un atributo poco importante para la mayoría de los casos analizados $(21,07 \%$ importancia relativa muestra completa). En este contexto, el atributo aseguramiento de la calidad aparece como el más importante guiando las decisiones del consumidor de carne de vacuno $(29,75 \%$ importancia relativa muestra completa). Si bien existen algunas limitaciones en este estudio, es interesante destacar que los resultados presentados aquí siguen las tendencias descritas en investigaciones previas realizadas en otros países. Por lo tanto, estas tendencias deberían ser tomadas en cuenta para establecer herramientas de diferenciación estratégica a la hora de diseñar una mezcla de marketing dirigida al mercado local.

Palabras clave: análisis conjunto, país de origen, bienestar animal, aseguramiento de la calidad, diferenciación, marketing.

\section{LITERATURE CITED}

Aaker, D., V. Kumar, and G. Day. 2003. Marketing research. $8^{\text {th }}$ ed. 800 p. John Wiley and Sons, New York, USA.

Intelliquest. 2000. Preference structure measurement: conjoint analysis and related techniques. $36 \mathrm{p} .2^{\text {nd }}$ ed. American Marketing Association (AMA), New York, USA.

Bech-Larsen, T., and K. Grunert. 2003. The perceived healthiness of functional foods. A conjoint study of Danish, Finnish and American consumers' perception of functional foods. Appetite 40:9-14. 
Becker, T. 2000. Consumer perception of fresh meat quality: A framework for analysis. Br. Food J. 102:158-176.

Becker, T., E. Benner, and K. Glitsch. 2000. Consumer perception of fresh meat quality in Germany. Br. Food J. 102:246-266.

Belcher, K., A. Germann, and J. Schmutz. 2007. Beef with environmental and quality attributes: preferences of environmental group and general population consumers in Saskatchewan, Canada. Agric. Human Values 24:333-342.

Bernabéu, R., and A. Tendero. 2005. Preference structure for lamb meat consumers. A Spanish case study. Meat Sci. 71:464-470.

Bernués, A., A. Olaizola, and K. Corcoran. 2003a. Extrinsic attributes of red meat as indicators of quality in Europe: an application for market segmentation. Food Qual. Prefer. 14:265-276.

Bernués, A., A. Olaizola, and K. Corcoran. 2003b. Labelling information demanded by European consumers and relationships with purchasing motives, quality and safety of meat. Meat Sci. 65:1095-1106.

Cattin, P., and D. Wittink. 1982. Commercial use of conjoint analysis: a survey. J. Marketing 46:44-53.

European Commission. 2005. Consumer protection in the European Union. Ten basic principles. Directorate General for Health and Consumer Protection, Brussels. Belgium. Available at http://ec.europa.eu/ consumers/cons_info/10principles/en.pdf (accessed July 2008).

Fotopoulos, C., and A. Krystallis. 2003. Quality labels as a marketing advantage. The case of the "PDO Zagora" apples in the Greek market. Eur. J. Marketing 37:1350-1374.

Gallo, C., G. Lizondo, and T. Knowles. 2003. Effects of journey and lairage time on steers transported to slaughter in Chile. Vet. Rec. 152:361-364.

Glitsch, K. 2000. Consumer perceptions of fresh meat quality: cross-national comparison. Br. Food J. 102:177-194.

Green, P., and V. Srinivasan. 1978. Conjoint analysis in consumer research: issues and outlook. J. Consum. Res. 5:103-123.

Green, P., and V. Srinivasan. 1990. Conjoint analysis in marketing: new developments with implications for research and practice. J. Marketing 54:3-19.

Hair, J., R. Anderson, R. Tatham, y W. Black. 1999. Análisis multivariante. 832 p. $5^{\text {th }}$ ed. Prentice Hall Iberia, Madrid, España.

Halbrendt, C., Q. Wang, C. Fraiz, and L. O'Dierno. 1995. Marketing problems and opportunities in mid-Atlantic seafood retailing. Am. J. Agric. Econ. 77:1313-1318.
Harrison, R., A. Özayana, and S. Meyers. 1998. A conjoint analysis of new food products processed from underutilized small crawfish. J. Agric. Appl. Econ. 30:257-265.

Hatanaka, M., C. Bain, and L. Busch. 2005. Third-party certification in the global agrifood system. Food Policy 30:354-369.

Hoffmann, R. 2000. Country of origin - a consumer perception perspective of fresh meat. Br. Food J. 102:211-229.

Huang, C., and J. Fu. 1993. Consumer preferences and evaluations of a processed meat product. J. Food Distrib. Res. 24:149-157.

Jaeger, S., D. Hedderley, and H. MacFie. 2001. Methodological issues in conjoint analysis: A case study. Eur. J. Marketing 35:1217-1237.

Jahn, G., M. Schramm, and A. Spiller. 2005. The reliability of certification: Quality labels as a consumer policy tool. J. Consum. Policy 28:53-73.

Javalgi, R., V. Pioche Khare, A. Gross, and R. Scherer. 2005. An application of the consumer ethnocentrism model to French consumers. Int. Bus. Rev. 14:325-344.

Kaynak, E., and A. Kara. 2002. Consumer perceptions of foreign products: An analysis of product-country images and ethnocentrism. Eur. J. Marketing 36:928949.

Knight, G. 1999. Consumer preferences for foreign and domestic products. J. Consum. Marketing 16:151162.

Lancaster, K. 1966. A new approach to consumer theory. J. Polit. Econ. 74:132-157.

Lockshin, L., W. Jarvis, F. d'Hauteville, and J. Perrouty. 2006. Using simulations from discrete choice experiments to measure consumer sensitivity to brand, region, price, and awards in wine choice. Food Qual. Prefer. 17:166-178.

Lovelock, C., R. Stiff, D. Cullwick, and I. Kaufman. 1976. An evaluation of the effectiveness of drop-off questionnaire delivery. J. Marketing Res. 13:358-364.

Meehan, H., C. Cowan, and B. McIntyre. 2002. Food choice and consumer concerns about animal welfare in Ireland. p. 19. The National Food Centre, Dublin, Ireland.

Mesías, F., M. Escribano, A. Rodríguez de Ledesma, and F. Pulido. 2005. Consumers' preferences for beef in the Spanish region of Extremadura: a study using conjoint analysis. J. Sci. Food Agric. 85:2487-2494.

Murphy, M., C. Cowan, H. Meehan, and S. O'Reilly. 2004. A conjoint analysis of Irish consumer preferences for farmhouse cheese. Br. Food J. 106:288-300.

Northen, J. 2000. Quality attributes and quality cues. Effective communication in the UK meat supply chain. Br. Food J. 102:230-245. 
O'Connor, E., C. Cowan, G. Williams, J. O'Connell, and M. Boland. 2005. Acceptance by Irish consumers of a hypothetical GM dairy spread that reduces cholesterol. Br. Food J. 107:361-380.

O'Connor, E., C. Cowan, G. Williams, J. O'Connell, and M. Boland. 2006. Irish consumer acceptance of a hypothetical second-generation GM yogurt product. Food Qual. Prefer. 17:400-411.

Padilla, C., P. Villalobos, A. Spiller, and G. Henry. 2007. Consumer preference and willingness to pay for an officially certified quality label: Implications for traditional food producers. Agric. Téc. (Chile) 67:300-308.

Pérez, C. 2005. Técnicas estadísticas con SPSS 12.824 p. Pearson Educación S.A., Madrid, España.

Shimp, T., and S. Sharma. 1987. Consumer ethnocentrism: construction and validation of the CETSCALE. J. Marketing Res. 24:280-289.

Spiller, A. 2003. Nuevas orientaciones para el aseguramiento de la calidad en la cadena agroalimentaria. p. 34-66. In Conferencia Internacional sobre Gestión de la Calidad en la Cadena Agroalimentaria, Santiago, Chile. Marzo de 1998. Instituto Interamericano de Cooperación para la Agricultura (IICA), Santiago, Chile.

Tadich, N., C. Gallo, y M. Alvarado. 2000. Efecto de 36 horas de transporte terrestre con y sin descanso sobre algunas variables sanguíneas indicadoras de estrés en bovinos. Arch. Med. Vet. 32:171-183.
Tendero, A., and R. Bernabéu. 2005. Preference structure for cheese consumers. A Spanish case study. Br. Food J. 107:60-73.

Van der Lans, I., and K. van Ittersum. 2001. The role of region of origin and EU certificates of origin in consumer evaluation of food products. Eur. Rev. Agric. Econ. 28:451-477.

Varela, J., y T. Braña. 1996. Análisis conjunto aplicado a la investigación comercial. 116 p. Ediciones Pirámide S.A., Madrid, España.

Verbeke, W., and R. Ward. 2006. Consumer interest in information cues denoting quality, traceability and origin: an application of ordered probit models to beef labels. Food Qual. Prefer. 17:453-467.

Villalobos, P. 2005. Bienestar animal como atributo de diferenciación en la decisión de compra de los consumidores. p. 139-147. In G. González et al. (eds.) La institucionalidad del bienestar animal, un requisito para su desarrollo normativo, científico y productivo, Santiago, Chile. 11-12 de noviembre de 2004. Servicio Agrícola y Ganadero, Santiago, Chile.

Walley, K., S. Parsons, and M. Bland. 1999. Quality assurance and the consumer. A conjoint analysis. Br. Food J. 101:148-161.

Watson, J., and K. Wright. 2000. Consumer ethnocentrism and attitudes toward domestic and foreign products. Eur. J. Marketing 34:1149-1166.

Wittink, D., and P. Cattin. 1989. Commercial use of conjoint analysis: an update. J. Marketing 53:91-96. 